\title{
THE CLINICAL STUDY \& TREATMENT OF SICK CHILDREN.
}

\author{
By John Thomson \& Leonard Findlay.
}

Fifth Edition. pp. xxxvi, 1075.

Oliver \& Boyd, Edinburgh and London. Price, 30/-.

It is not a light matter to undertake the re-issue of a book which through successive editions, extending from 1898 to 1925 , was universally recognised as possessing a peculiar charm and distinction, due in part to the personal qualities of its author and in part to his special professional experiences. The claim in such a situation is to preserve the clinical and literary tradition on the one hand, and, on the other, to secure the additions and modifications which the progress of knowledge inevitably demands. These two obligations have faced Dr. Findlay in the re-writing of the volume so long and happily associated with the name of the late Dr. Jno. Thomson, and he has shown himself not unequal to the event. Hence, in a word, the fifth edition may fairly claim to be both worthy of its classical predecessors and also well equipped with modern knowledge and methods. As a text-book treating of disease in children it has many attractive qualities, and among these not the least is the teaching based upon the direct personal and clinical experience of the two authorities whose names appear on the title page: it claims to be a clinical study, and while not neglecting laboratory results it finds its doctrines, its directions, and its records mainly at the bedside.

The whole of the book has been thoroughly reviewed, and among recent developments full attention has been given to these in relation to nutritional disease in infancy, to the acid intoxications and to tuberculosis, while Dr. Findlay's original studies on rickets, rheumatism, tetany, bronchiectasis and other subjects give a special interest to the corresponding sections. In its new guise the book is sure of a continued career of success and of service; a special word of recognition is due to the illustrations and to the abundant referencest to original articles; and the publisher and printer have fully succeeded in their respec-? tive departments.

\section{THE TREATMENT OF RHEUMATISM IN GENERAL PRACTICE.}

\author{
By W. S. C. Copeman, M.A., M.B., M.R.C.P. \\ Edward Arnold and Co. Price, 9/- net. pp. 215.
}

To use the words of the author, this book is designed to "fill a gap which appears to exist in the literature of rheumatic diseases." It is a beautifully clear exposition of the main clinical features, and the treatment of the conditions which come under this heading. The matter is set out in a clear and scholarly fashion, and is the result of wide reading and personal observation of a large number of cases, on the part of the author. So often a practitioner is faced with many different proprietary preparations which a patient may wish to try: or perhaps he needs guidance as to the use of physical measures such as various heat or light rays; or the time and place for manipulation. $\mathrm{He}$ will find this volume answers many of his doubts, without bias in any one direction.
It would be of advantage if the treatment of juvenile rheumatism was considered in greater detail, or else omitted altogether, as this section of the book (13 pages) will give little help to the practitioner. The value of the sedimentation rate in juvenile rheumatism could be mentioned with profit. In the section on adult rheumatism, there is scanty mention of the cases of arthritis associated with tabes and syringomyelia, and no mention of Clutton's joints.

On the whole this is an extremely good book which will prove of great value to the practitioner, and will enable him to treat his cases of rheumatism with much greater. confidence, and often much better results. 